\title{
Erratum to: Stress, burnout, and job dissatisfaction in mental health workers
}

\author{
Wulf Rössler ${ }^{1,2,3}$
}

Published online: 19 April 2016

(C) Springer-Verlag Berlin Heidelberg 2016

\section{Erratum to: Eur Arch Psychiatry Clin Neurosci (2012) 262 (Suppl 2):S65-S69 DOI 10.1007/s00406-012-0353-4}

Unfortunately, the Maslach Burnout Inventory (MBI) was published in detail in Table 1 of the above named article without permission of the publisher.

Therefore, Table 1 was removed from the article and replaced by an appropriate information text.

The complete Maslach Burnout Inventory can be purchased from the publisher Mind Garden, Inc. (www.mindgarden.com).

The author apologizes for any inconveniences caused.

The online version of the original article can be found under doi:10.1007/s00406-012-0353-4.

Wulf Rössler

roessler@dgsp.uzh.ch

1 Department of General and Social Psychiatry,

Psychiatric University Hospital, University of Zurich,

Militärstrasse 8, 8004 Zurich, Switzerland

2 Collegium Helveticum (a joint Research Institute between the University of Zurich and the Swiss Federal Institute of Technology), Zurich, Switzerland

3 Leuphana University, Lüneburg, Germany 